\title{
Correction to: Hardware-in-the-Loop Simulation of High-Power Modular Converters and Drives
}

Christian Dufour, Karthik Palaniappan, and Brian J. Seibel

\section{Correction to:}

Chapter 2 in: W. Zamboni, G. Petrone (eds.), ELECTRIMACS 2019, Lecture Notes in Electrical Engineering 604, https://doi.org/10.1007/978-3-030-37161-6_2

The original version of this chapter was revised due to the term " $20-50 \mu$ s" being erroneously changed to "20-50 $\mu \mathrm{m}$ ". The occurrence appears on the first page, line 17 , of the chapter. 